\title{
THE INFLUENCE OF NATURAL AND MODEL FORMS OF HUMIC ACIDS ON THE DYNAMIC PARAMETERS OF MODEL MEMBRANES
}

\author{
WPEYW NATURALNYCH I MODELOWYCH KWASÓW HUMINOWYCH \\ NA DYNAMICZNE PARAMETRY BLON MODELOWYCH
}

\begin{abstract}
In this paper the influence of humic acid concentrations extracted from Histosols (HA-A) and their model forms (HA-B) separated from humic substances commercially produced by Carl Roth $\mathrm{GmbH}+\mathrm{Co} . \mathrm{KG}$ on the dynamic properties of liposome membranes was determined. Differences in the quality of the humic acids (HA-A and HA-B) were determined by the ${ }^{1} \mathrm{HNMR}$ and FTIR methods. Liposomes from the sonication of egg yolk lecithin (EYL) in an aqueous solution and synthetic Dipalmitoylphosphatidylcholine (DPPC) were used. Fluidity of liposome membranes was determined by the EPR technique with spin probes (TEMPO, 16DOIXYL). The electrical parameters of membranes were found using a Keithley 6517 electrometer. Our study showed significant differences in the influence of HA-A and HA-B on the membranes. In the bilayer membranes of the liposomes of HA-A admixture there was slightly more stiffening of the interior of the membrane in comparison to HA-B. A similar effect was observed in the surface layer of the liposome membranes. This difference is particularly evident for DPPC liposomes, however, the EYL liposomes admixture with HA-B slightly increased the fluidity of the surface layer. Electrical study confirmed this effect. The study shows that natural and model forms of humic acids differ in their effects on the activity of tested membrane models. The strong differences in the interaction of HA-A and HA-B on parameter F in DPPC liposomes can be result from the transport of humic acids connected to the metal ions inside the membranes (xenobiotics present in the environment).
\end{abstract}

Keywords: lecithin liposomes, ESR, ${ }^{1} \mathrm{HNMR}$, humic acid, spin label

\section{Introduction}

Frequently humic substances (HS) are referred to as the most comprehensive and most 'elusive' compounds in nature [1-3]. According to the commonly used definition proposed by IHSS, 'humic substances are complex and heterogeneous mixtures of polydispersed materials formed in soils, sediments and natural waters by biochemical and chemical

\footnotetext{
${ }^{1}$ Pedology Team, Department of Land Protection, University of Opole, ul. Oleska 22, 45-052 Opole, Poland, email: izapis@uni.opole.pl,karolinka203@op.pl

${ }^{2}$ Biophysical Team, Institute of Physics, University of Opole, ul. Oleska 48, 45-052 Opole, Poland, email: dariusz.man@uni.opole.pl,pytel@uni.opole.pl,rolch@uni.opole.pl,gengel@uni.opole.pl

${ }^{3}$ Embryology Laboratory, Medical Center „Antrum”, ul. Olimpijska 5, 41-902 Bytom, Poland, email: anet31@ poczta.onet.pl

*Corresponding author: izapis@uni.opole.pl
} 
reactions during the decay and transformation of plant and microbial remains' [4]. Their activity and mobility in the environment depend on the amount and quality of functional groups and their degree of aromaticity and aliphaticity. The fractional groups, in decreasing order of typical content are: carboxyl, phenolic and alcoholic hydroxyl, quinine and ketonic carbonyl, nitrogen- and sulphurcontaining groups [5,6]. The prevalence of carboxyl and phenolic hydroxyl groups is responsible for their net negative charge in natural waters and their behavior as polyelectrolytic compounds.

Thus, as research has shown, their structures can be modified by the quality of the environment where they are formed $[1,2,7,8]$. Commonly used methods of extracting these compounds from the natural environment can also modify their internal structure (changes in $\mathrm{pH}$, ionic strength, oxidation, hydrolysis, etc.). As a result it is difficult to study their natural structure and to compare their effects on living organisms through biological membranes.

Due to the great structural, phasal and dynamic complexity of the biological membranes, research on their biophysical properties is very often performed on model systems. Experimental models of biological membranes are usually layers (or multilayeros), double formed from one or more types of lipids, sometimes containing a controlled amount of other components. Liposomes serve as a good model for biological membranes. Studies carried out with liposomes have made it possible to predict, for example, the strong biological activities of tin - organic compounds [8-12]. It seems that research using membrane models can play an important role in understanding the mechanisms which determine the condition of living organisms, since biological membranes are involved in almost all aspects of cell activity.

They regulate the transport of external substances from the environment to the cell interior and going the opposite direction, they determine the formation of tonicity and functionality. They are involved in energy metabolism, simultaneously enabling the competitive overlap of chemical reactions, which is reflected in their dynamic properties [13].

Researchers have shown [3, 8, 14-17] that HS are not just components of the soil but are also found in various biological substances and are indication factors of biochemical processes that significantly modify the fluidity of membrane models. Our previous studies [18] found that structural differences of HS have varying affects on the fluidity of biological membrane models - liposomes.

The aim of this work was to demonstrate the structural diversity of humic acids extracted from peat and model forms of HS as well as their varying effect on the dynamic properties of the liposome membranes formed from lecithin EYL (natural) and synthetic lecithin DPPC.

\section{Materials and methods}

\section{Humic substances (HS)}

Peat, an organic soil, was taken from surface horizons of Histosols. Model forms of HS, containing 30-40\% of humic acids (HA-A) was made by Carl Roth GmbH + Co. KG. Humic acid extraction and purification were carried out by the IHSS method [14] as follows: humic substances were isolated by extraction of $10 \mathrm{~g}$ of peat with an aqueous solution of $\mathrm{NaOH} 0.5$ mole followed by centrifuging at room temperature and was precipitated at $\mathrm{pH}<1.5$. Humic acids were separated from fulvic acids by centrifugation, 
washed with distilled water in order to get a neutral $\mathrm{pH}$, shaken with a mixture of $\mathrm{HF}$ and $\mathrm{HCl}$ at room temperature for $24 \mathrm{~h}$, washed again with distilled water to a neutral $\mathrm{pH}$. Humic acids of model humic substances (HA-B) were isolated in the same way, using $1 \mathrm{~g}$ of humic substances made by Carl Roth GmbH + Co. KG. For FTIR analysis both humic acids were dried at $60^{\circ} \mathrm{C}$ under vacuum and weighed. FTIR spectra of humic acids at $4000-400 \mathrm{~cm}^{-1}$ absorption region were taken using fourier transformation spectrometer Nicolet NEXUS FT-IR spectrometer (Thermo Nicolet, USA 2002).

${ }^{1} \mathrm{H}$ NMR analyses were done using a Bruker NMR spectrometer (Germany 2005) $400 \mathrm{MHz}$ UltraShield at $22^{\circ} \mathrm{C}$. For the measurements, a $0.5 \mathrm{~cm}^{3}$ sample containing $20 \%$ $\mathrm{D}_{2} \mathrm{O}(\mathrm{v} / \mathrm{v})$ was used.

${ }^{1} \mathrm{H}$ NMR spectra were taken with a spectral width $s w=9615 \mathrm{~Hz}$, acquisition time $a q=3.4 \mathrm{~s}$ and relaxation delay $d 1=3 \mathrm{~s}$. During the measuring time, 14 minutes, 128 scans were collected, which included 65,536 points. The strong water signal was suppressed by water suppression by presaturation. The same methodology was used in our previous work [18].

The content of organic carbon in the solutions of used humic acids was determined by Analyzer Multi N/C 3100 (Analytikjena, Germany 2013). The analyzed humic acid contents were respectively: HA-A: $2951 \mathrm{mg} / \mathrm{dm}^{3}$, HA-B $1722 \mathrm{mg} / \mathrm{dm}^{3}$.

\section{Liposomes}

The liposomes used in this experiment were prepared by sonication of Egg Yolk Lecithin (EYL, isolated from fresh egg yolks) and synthetic lecithin (DPPC, produced by Sigma - Aldrich Company) in distilled water using ultrasonic disintegrator UD-20 (TECHPAN, Warsaw, Poland). The procedure used for isolation and purification of lecithin was a modification of the method described by Singleton et al [19]. The total time of sonication of single samples $\left(2 \mathrm{~cm}^{3}\right)$ was $10 \mathrm{~min}$ and took place in 10 alternating cycles of $30 \mathrm{~s}$ of sonication, $30 \mathrm{~s}$ of cooling. The concentration of lecithin in the samples was $0.04 \mathrm{M}$. After sonication, spin probes at a concentration of $1000 \mathrm{ppm}$ in relation to the lecithin were added to the sample.

\section{EPR technique}

To study changes in liposome membrane fluidity with admixtures of humic acid the ESR technique was used with spin probes: 2,2,6,6-tetramethylpiperidine-1-oxylane (TEMPO) and 2-ethyl-2-(15-methoxy-15-oxopentadecyl)-4,4-dimethyl-3-oxazolidinyloxy (16-DOXYL stearic acid methyl ester) (Fig. 1).

The probes were purchased from Sigma-Aldrich Company, Poland. Spin probe concentrations in the samples ranged from 0.01 to $0.005 \%$ of mol in relation to the lecithin. Figure 2 presents examples of spin probe spectra placed in an aqueous dispersion of liposomes.

Based on the fission of the high-field amplitude line of probe TEMPO (a) partition coefficient $F$ was determined. This parameter indicates the allocation of the probe between the liquid phase (line P), and the lipid phase (line $\mathrm{H}$ ). Changes of parameter $\mathrm{F}$ indicate the migration of the probe from one environment to another, which may indicate changes in fluidity [11]. On the basis of the spectra of probe 16-DOXYL (b) rotation correlation time $\tau$ was determined $\left(\tau=5.95 \Delta H\left(\left(I_{0} / I_{+1}\right)^{1 / 2}+\left(I_{0} / I_{-1}\right)^{1 / 2}-2\right) 10^{-10}\right.$. An parameter $\tau$ increase was followed by increased stiffness of the liposome membranes [20]. Due to the complex structure of humic acid, concentrations by weight were used, which in relation to lecithin 
varied from 0 to $12 \%$. In order to thoroughly mix the ingredients, each of the samples was shaken $600 \mathrm{~s}$ (using a microshaker with polypropylene tubes) before measuring and then placed in a measuring chamber spectrometer (in glass capillaries of $1 \mathrm{~mm}$ diameter and capacity approx. $0.04 \mathrm{~cm}^{3}$ ). The ESR measurements were performed at a constant temperature of $20^{\circ} \mathrm{C}$, and the total time of the measurement series was no more than $3 \mathrm{~h}$ for each sample. ESR spectrometer (MX-201R ESR spectrometer TU Wroclaw, Poland) operating parameters were: microwave power $P=50 \mathrm{~mW}$, sweep range $\Delta H=7 \mathrm{mT}$, amplitude modulation $d H=0.08 \mathrm{mT}$, time constant $d t=0.3 \mathrm{~s}$, sweep time $t=128 \mathrm{~s}$.

TEMPO

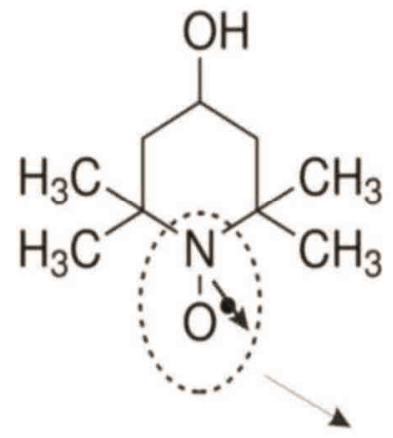

16-Doxyl-stearic acid methyl ester

\section{Nitroxyl group}

Fig. 1. Structural formulas of used spin probes

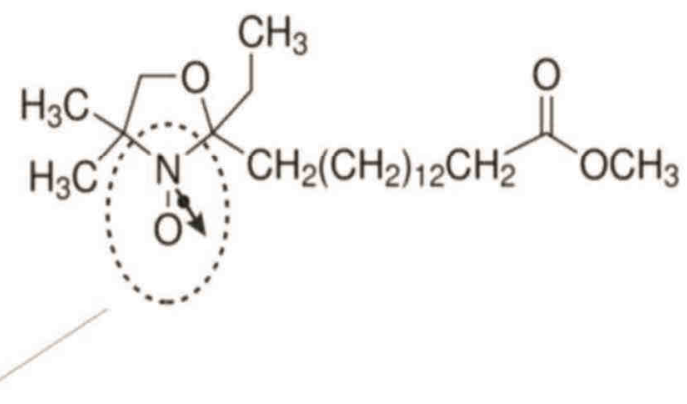

a)

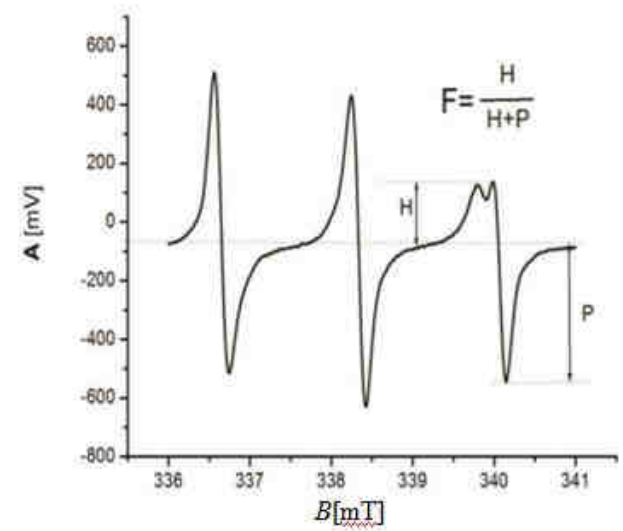

b)

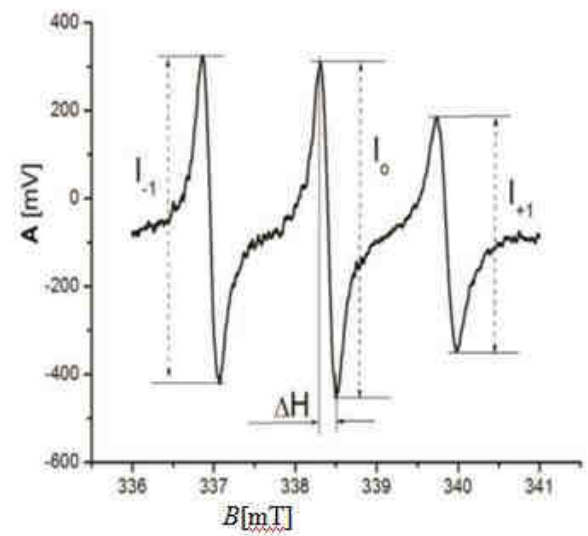

Fig. 2. ESR spectra of spin probes placed in the liposome membrane: a) TEMPO probe and spectroscopic partition parameter $(\mathrm{F})$; b) 16-DOXYL - stearic acid methyl ester probe and parameter $(\tau)$ 


\section{Electric method}

Parallel to the ESR studies, the electrical properties of membranes modified by selected humic acid were investigated. The membranes were made of nitrocellulose filters, produced by Synpor. Before the measurement they were then impregnated with lauric acid butyl ester $\left(\mathrm{C}_{4} \mathrm{H}_{9} \mathrm{COOC}_{12} \mathrm{H}_{23}\right)$. Filter diameter was 1.5 and $50 \mu \mathrm{m}$ thick. Membrane $\mathrm{M}$ (Fig. 3) separates the reference chamber (2) from the measuring chamber (1).

Initially the chambers were filled with $0.01 \mathrm{M} \mathrm{KCl}$ solution. The trans-membrane voltage, due to the presence of the two humic acids in the measuring chamber, was determined using Keithley 6517 electrometer and $\mathrm{Ag} / \mathrm{AgCl}$ electrode system (Fig. 3). The concentration of compounds in the test chamber was changed $0-0.024 \%$ relative to the water.

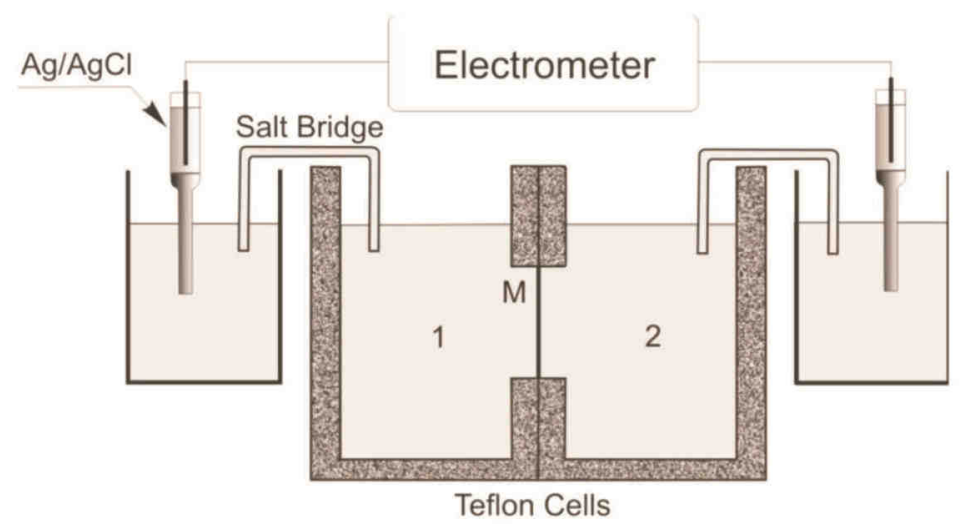

Fig. 3. A scheme of voltage measuring system, where $M$ indicates a membrane separating the measuring (1) and reference (2) chambers

\section{Results and discussion}

\section{IR spectroscopy}

As illustrated in Figures 4 and 5, and Table 1, spectra of humic acids extracted from peat and model forms of HS indicate the presence of similar absorption zones with differing intensities.

In both substances the strongest expression in the absorption zone was in the range of $3600-3000 \mathrm{~cm}^{-1}$, corresponding to the $-\mathrm{OH}$ group of phenols and alcohols. Generally, next to this zone, there is a marked absorption at 3000-2800 $\mathrm{cm}^{-1}$, characteristic of the $-\mathrm{CH}$ bonds extending methyl groups $-\mathrm{CH}_{3}$. In the analyzed spectra this signal was not observed. The absorption zones corresponding to vibrations extending in the carboxyl groups occurred in the range of 1705 and $1706 \mathrm{~cm}^{-1}$. The area ranging from 1500 to $1107 \mathrm{~cm}^{-1}$ has a low intensity in the HA-B, as well as the presence of vibrations of the scissor groups $-\mathrm{CH}$ $\left(1455 \mathrm{~cm}^{-1}\right)$, and deformation of the $-\mathrm{OH}$ groups of phenols (less than $1401 \mathrm{~cm}^{-1}$ in the HA-B, and less than $1405 \mathrm{~cm}^{-1}$ in the HA-A). The absorption bands in the area of $1158 \mathrm{~cm}^{-1}$ in the 'model forms' and in both areas of 1207 as well as $1078 \mathrm{~cm}^{-1}$ in the peat are responsible for the presence of ester bond stretching vibrations of C-O. Spectral range from 900 to $675 \mathrm{~cm}^{-1}$ together with the presence of vibrations in the range of $1600 \mathrm{~cm}^{-1}$ 
may indicate the presence of aromatics. This range has low absorbance, reflecting the strongly expressed aliphatic nature of the structures of both forms of humic acids. Moreover, the absence of an absorption band extending slightly above $3000 \mathrm{~cm}^{-1}$ also confirms that both fractions of humic acids have a highly expanded aliphatic part of their structures [14, 15, 18, 21-23].

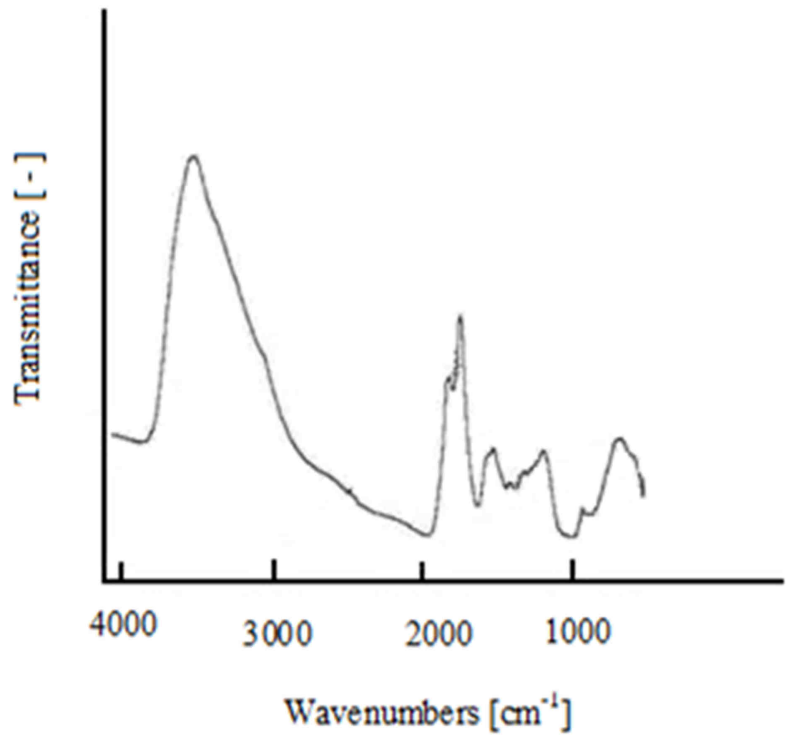

Fig. 4. FTIR spectra of humic acids extracted from peat (HA-A)

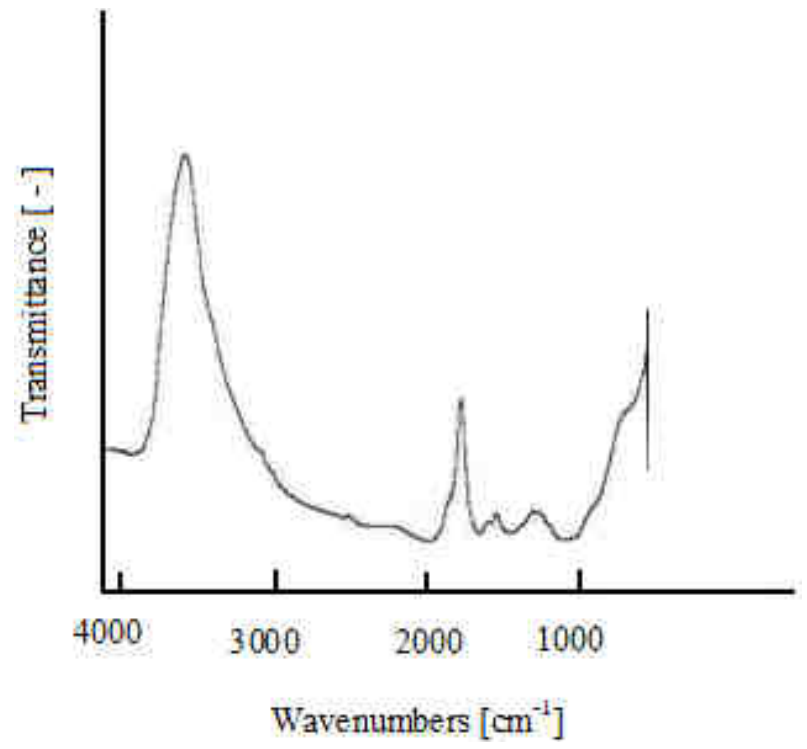

Fig. 5. FTIR spectra of humic acids extracted from humic substances (HA-B) 
Absorption zones of humic acids [15, 21, 22]

Table 1

\begin{tabular}{|c|c|c|c|c|}
\hline Functionality & FTIR $\left[\mathrm{cm}^{-1}\right]$ & Type & HA-A & HA-B \\
\hline $\mathrm{CH}_{3}$ & $3000-2850$ & extending & no & no \\
\hline $\mathrm{CH}_{2}$ & $\begin{array}{l}2950-2850 \\
2875-2800\end{array}$ & $\begin{array}{l}\text { extending } \\
\text { extending }\end{array}$ & no & no \\
\hline $\mathrm{CH}$ & $1300-1100$ & deformation & no & no \\
\hline $\mathrm{HC}=\mathrm{CH}$ & $\begin{array}{l}3100-3000 \\
1420-1290\end{array}$ & $\begin{array}{c}\text { extending } \\
\text { deformation }\end{array}$ & no & no \\
\hline$\equiv \mathrm{C}-\mathrm{OH}$ & $\begin{array}{l}3500-3100 \\
2260-2100 \\
1370-1220\end{array}$ & $\begin{array}{c}\text { extending } \\
\text { extending } \\
\text { deformation }\end{array}$ & no & no \\
\hline $\begin{array}{l}\mathrm{OH} \text { alcohols and } \\
\text { phenols }\end{array}$ & $\begin{array}{l}3600-3000 \\
1210-1120 \\
1125-1090 \\
1075-1050\end{array}$ & $\begin{array}{l}\text { extending } \\
\text { extending } \\
\text { extending } \\
\text { extending }\end{array}$ & 3405 & 3426 \\
\hline$-\mathrm{COH}$ & $\begin{array}{c}2900-2700(\mathrm{H}) \\
1750-1650(\mathrm{C}=\mathrm{O})\end{array}$ & $\begin{array}{l}\text { extending } \\
\text { extending }\end{array}$ & no & no \\
\hline $\mathrm{COOH}$ & $\begin{array}{c}3300-2900(\mathrm{OH}) \\
1775-1675(\mathrm{C}=\mathrm{O}) \\
1725-1700(\mathrm{C}=\mathrm{O})\end{array}$ & $\begin{array}{c}\text { extending } \\
\text { deformation } \\
\text { deformation }\end{array}$ & $\begin{array}{l}1706 \\
1730\end{array}$ & 1705 \\
\hline$\equiv \mathrm{CNH}$ & $3500-3200$ & deformation & no & no \\
\hline $\mathrm{Ar}$ & $\begin{array}{l}3030 \\
\sim 1600 \\
\sim 1500 \\
\sim 1450 \\
\sim 750 \\
\sim 700 \\
\end{array}$ & $\begin{array}{c}\text { extending framework } \\
\text { extending framework } \\
\text { extending framework } \\
\text { extending } \\
\text { deformation } \\
\text { deformation } \\
\end{array}$ & 1629 & $\begin{array}{l}1455 \\
1630\end{array}$ \\
\hline fingerprint region & $\begin{array}{c}1450-1250(\mathrm{OH}) \\
1430-1050(\mathrm{C}-\mathrm{O}) \\
600-800(\mathrm{C}-\mathrm{Cl})\end{array}$ & $\begin{array}{l}\text { deformation } \\
\text { extending } \\
\text { extending }\end{array}$ & $\begin{array}{l}1078 \\
1207 \\
1305 \\
1405\end{array}$ & $\begin{array}{l}1158 \\
1401\end{array}$ \\
\hline
\end{tabular}

no - not observed

\section{${ }^{1}$ H NMR spectroscopy}

Analysis of ${ }^{1} \mathrm{H}$ NMR spectra of humic acids extracted from peat and model forms of HS (Figs. 6 and 7) confirms the aliphatic nature of their structural composition.

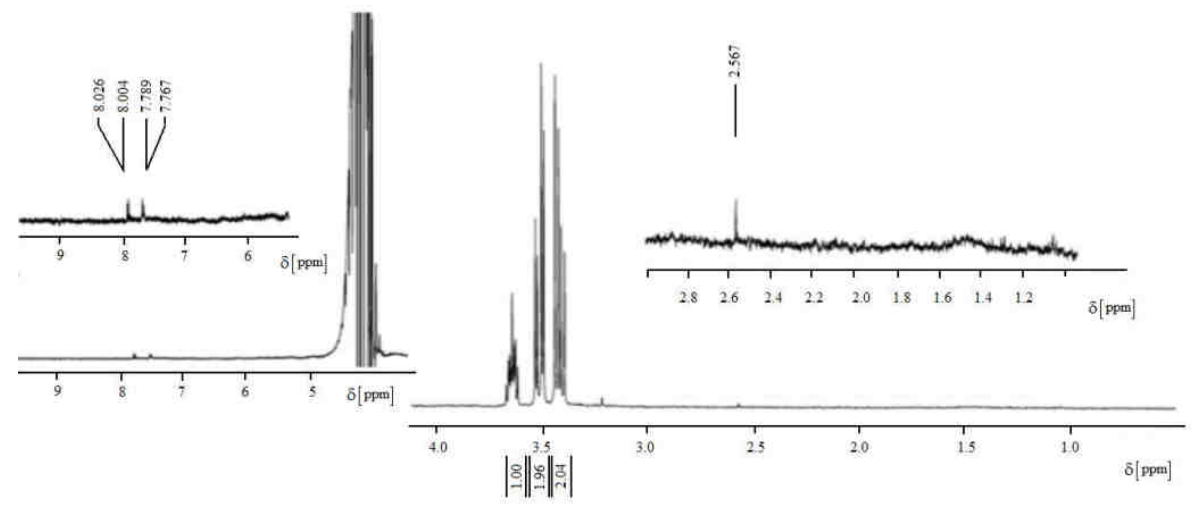

Fig. 6. ${ }^{1} \mathrm{H}$ NMR solution spectra of HA - humic acids extracted from used peat 


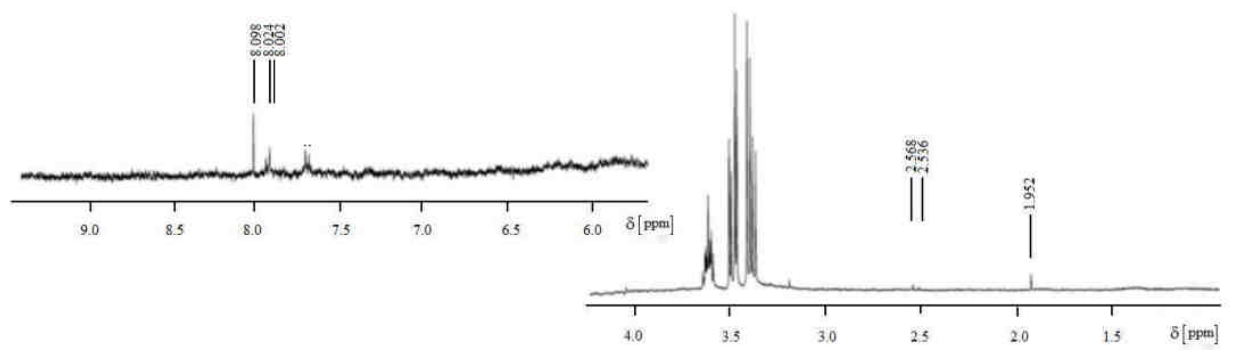

Fig. 7. ${ }^{1} \mathrm{H}$ NMR solution spectra of HA - humic acids extracted from used model forms of HS

Table 2 presents important diagnostic absorption of ${ }^{1} \mathrm{H}$ NMR spectra in general and analyzed humic acids.

Chemical shifts of ${ }^{1} \mathrm{HNMR}$ of humic acids [15, 18, 21-23]

Table 2

\begin{tabular}{|c|c|c|c|}
\hline Functionality & $\boldsymbol{\delta}^{1} \mathbf{H}[\mathbf{p p m}]$ & HA-A & HA-B \\
\hline $\mathrm{CH}_{3}$ & $0-1$ & no & no \\
\hline $\mathrm{CH}_{2}$ & $1-2$ & no & + \\
\hline $\mathrm{CH}$ & 1.5 & no & no \\
\hline $\mathrm{HC}=\mathrm{CH}$ & $4.6-5.9$ & + & + \\
\hline$\equiv \mathrm{C}-\mathrm{OH}$ & $2-3$ & + & + \\
\hline $\mathrm{OH}$ alcohols and phenols & $2-6$ & + & + \\
\hline $\mathrm{COOH}$ & $6-8.5$ & + & no \\
\hline$\equiv \mathrm{CNH}$ & $1-5$ & no & + \\
\hline $\mathrm{Ar}$ & $6-9.5$ & + & no \\
\hline $\mathrm{HC}-\mathrm{Ar}$ & $2.3-2.9$ & no & no \\
\hline $\mathrm{HC}=\mathrm{O}$ & $9-10$ & no & no \\
\hline $\mathrm{HO}-\mathrm{Ar}$ & $4-12$ & no & \\
\hline
\end{tabular}

no - not observed, + - presence

Taking into consideration chemical shifts, humic substances were used which are characterized by the presence of broad signals in the range of 3.4 to $3.7 \mathrm{ppm}$, associated with protons located on the carbon atom in alcohols. Simultaneously, the spectrum is attributed to the presence of glycerol, which may be the result of lipid hydrolysis during the extraction and purification of the humic acids, emphasized in our previous work [18].

${ }^{1} \mathrm{H}$ NMR spectra of humic acids, extracted from peats and model compounds, give signals connected with protons of aliphatic compounds $\delta \leq 2.5 \mathrm{ppm}$ (the presence of these signals was previously reported by Man et al [18, 23]). Comparative analysis of spectra of humic acids extracted from peat (HA-A) and the model forms (HA-B) indicates a high degree of similarity in their structure. There was a signal which was related to alkyl in the aliphatic chain $(2.5<\delta \leq 8.6 \mathrm{ppm})$ as well as the aromatic protons - signal in the range of $6.6 \leq \delta \leq 8.6 \mathrm{ppm}$. The area of the spectrum giving signals between 2.5-2.7 ppm includes a system consisting of several functional groups: amino, amide or methylene groups.

The signals, in the range of 3.75-3.92 ppm and associated with the presence of functional groups of protons, are typical for HS. They indicate the presence of repeating units of metylopropyl groups, which are structural units of lignin, and appropriate humic 
compounds [24]. This signal was not seen in any of the analyzed spectrum, confirming their aliphatic character.

\section{EPR spectroscopy}

Figure 8 shows the effect of the concentration of humic acids HA-A and HA-B on the spectroscopic properties of probe TEMPO $(\mathrm{F})$, placed in an aqueous dispersion of liposomes prepared from DPPC (Fig. 8a) and EYL (Fig. 8b).

a)

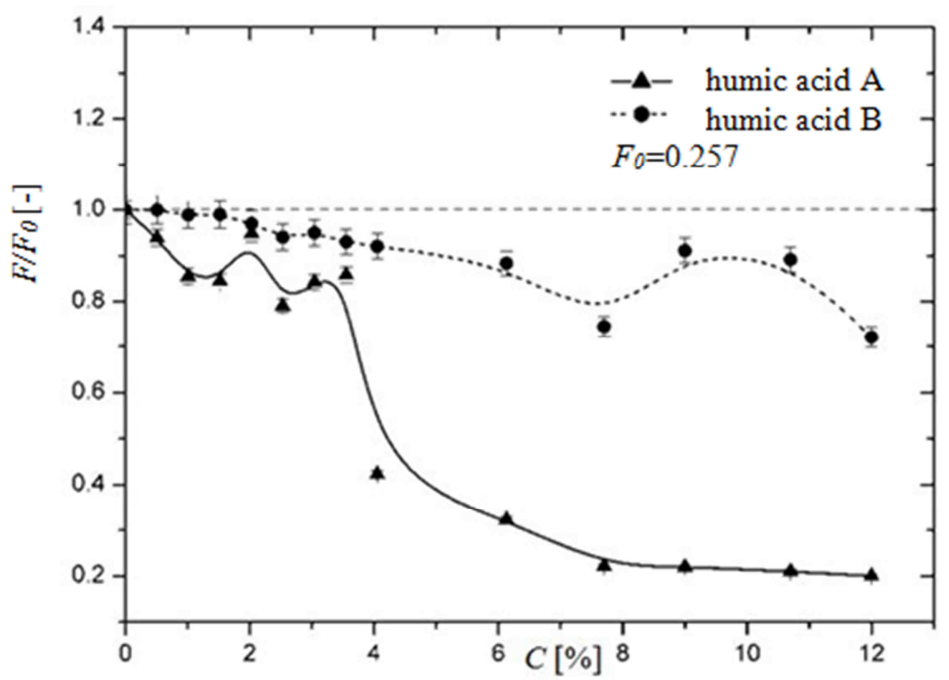

b)

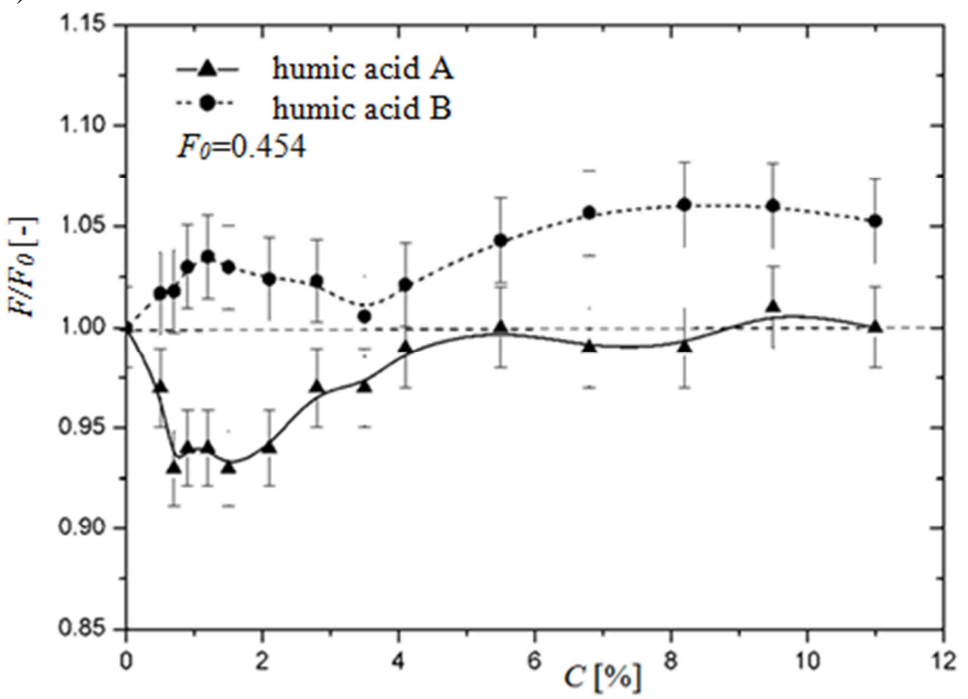

Fig. 8. The dependence of relative value of spin probe TEMPO placed in: a) the membrane of DPPC liposome, b) EYL liposome 
To highlight the changes caused by introducing the humic acids into the membranes, the charts show the portiton coefficient of the probe parameter $\left(F / F_{0}\right)$. The broken line shows the values of these parameters for liposomes without admixtures HA-A and HA-B. Points below this line mean that the membranes under the influence of humic acids are stiffening: the smaller the $F / F_{0}$, the greater the stiffness of the membrane.

a)

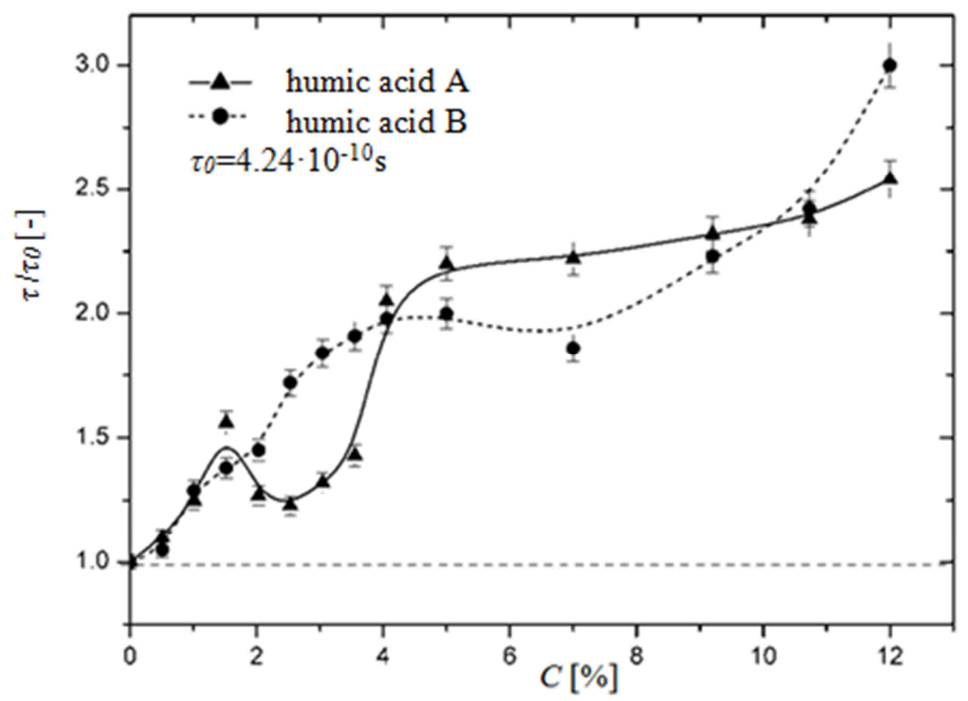

b)

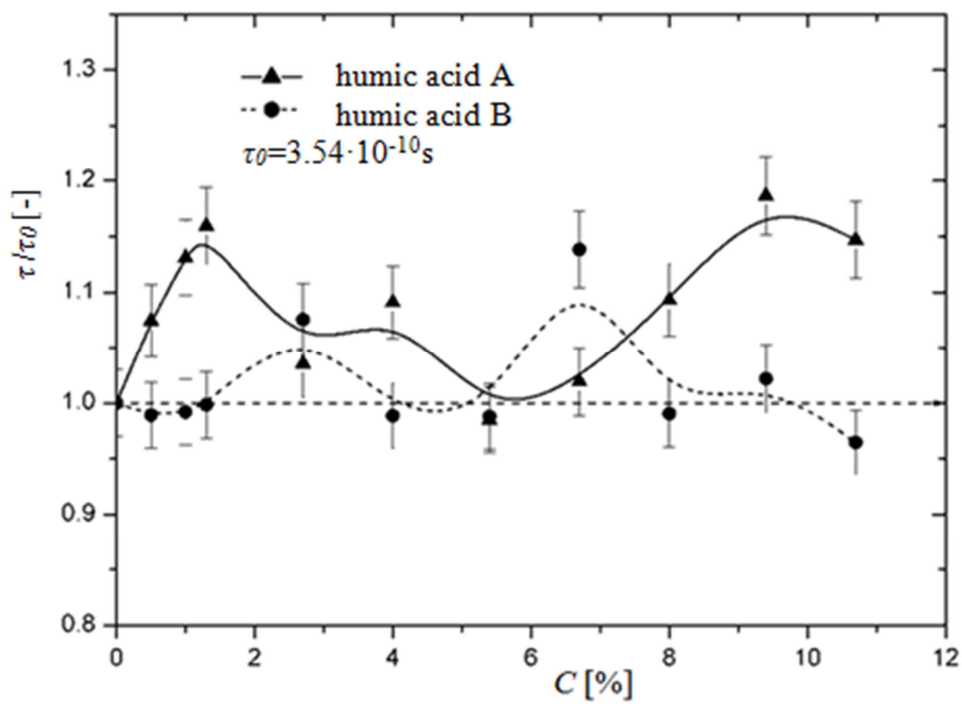

Fig. 9. The dependence of relative value of spin probe 16-DOXYL placed in: a) the membrane of DPPC liposome, b) EYL liposome 
From the data shown in Figure 8, we can observe that liposomes formed from DPPC were stiffened for both the HA fractions. There was much stronger stiffening for HA-A than HA-B. This is particularly evident for concentrations above $6 \%$, where parameter $F / F_{0}$ has a value of about 0.2 , whereas HA-B oscillates around 0.8. Liposomes formed from EYL are less susceptible to changes in their fluidity under the tested HA. In the case of HA-A admixtures a small minimum value of parameter $F / F_{0}(0.93)$ was found in a concentration range of $0.5-1.5 \%$.

Concentrations above $4 \%$ of HA-A admixture do not significantly alter membrane fluidity. Surprisingly, the EYL liposome membrane fluidity was affected by the admixture of HA-B. In contrast to previous cases, it slightly increased membrane fluidity - data arranged above the dotted line (Fig. 8). Changes in parameter $F / F_{0}$ stabilized at a level of 1.05 for concentrations above $6 \%$.

Figure 9 shows the effect of humic acid concentrations (HA-HA and HA-B) on the rotation correlation time $(\tau)$ of probe 16-DOXYL which was placed in the center of the bilayer of the liposome from DPPC (Fig. 9a) and EYL (Fig. 9b). To highlight the changes caused by the introduction of HA into the membranes, the charts present the rotation parameter correlation time $\left(\tau / \tau_{0}\right)$. The dotted line shows the value of these parameters for liposomes without admixture HA. Points located above the line indicate that the membrane under the influence of the admixtures was stiffening. The higher the value of the $\tau / \tau_{0}$ parameters, the greater the stiffening of the membrane.

Both fractions of HA greatly stiffen liposome membranes formed from DPPC (Fig. 9). The increase is approximately proportional to an increase in the concentration of HA, except for concentrations of HA-A between 0.5 to $1.5 \%$, in which parameter $\tau / \tau_{0}$ reaches a local maximum (1.5). For a concentration of $12 \%$ admixtures HA-A and HA-B, parameters $\tau / \tau_{0}$ reach their maximum values of 2.5 and 3. A decidedly weaker effect on membrane fluidity was observed in liposomes formed from EYL. With increasing HAs concentrations, values oscillated between 0.95-1.05 for HA-B and 1-1.2 for HA-A. There was no clear relationship between an increased HAs concentration and changes of parameter $\tau / \tau_{0}$.

\section{Voltage experiment}

Figure 10a and $\mathrm{b}$ present the influence of humic acid concentrations (HA-A and HA-B) on the transmembrane voltage generated between the measurement chamber and the control.

The dividing membrane $M$ (Fig. 3) resulted from the impregnation of the filter with lauric acid butyl ester. HA-A and HA-B concentrations are expressed as a per cent of weight to volume ratio:

$$
c_{x}=\frac{m_{x}}{V_{c}} \cdot 100 \%
$$

where: $m_{x}$ - humic acid weight, $V_{c}$ - measurement chamber volume.

The graphs indicate that together with increased admixture concentration the transmembrane voltage also increases. The influence of HA-A on the voltage was significantly greater than for the HA-B admixture. According to the Nernst equation:

$$
U=\frac{R T}{z F} \ln \frac{f_{1} c_{1}}{f_{0} c_{0}}
$$


where: $R$ - gas constant, $T$ - absolute temperature, $F$ - Faraday constant, $z$ - valence of ions, $c_{1}$ and $c_{0}$ - concentrations of redox fraction in the measurement and reference chambers respectively: $f_{1}$ and $f_{0}$ - ions activity coefficients.

a)

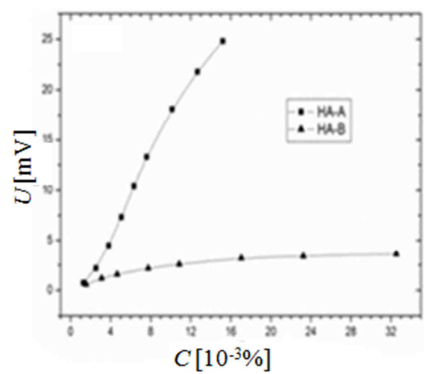

b)

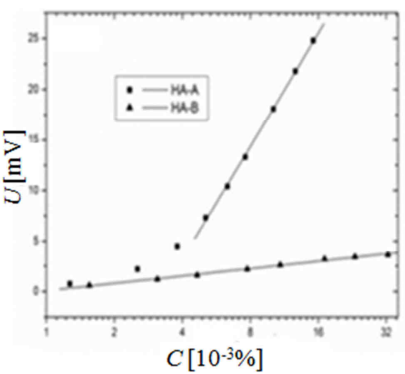

c)

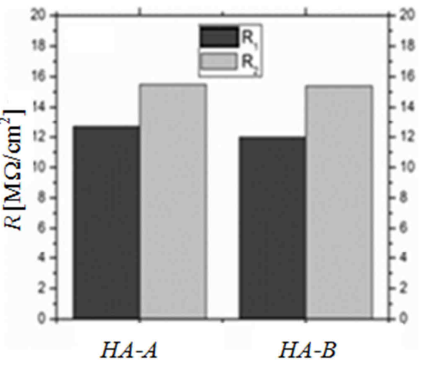

Fig. 10. Effect of humic acid concentrations on trans-membrane voltage in $C$ [\%]: a) normal scale, b) logarithmic scale, c) changes in the resistance of $R$ membranes $\left[\mathrm{M} \Omega / \mathrm{cm}^{2}\right]: R_{1}-$ initial, $R_{2}$ - final

The diagram of dependence $U=f(\ln c)$ should be a straight line. This occurred for the $\mathrm{H}-\mathrm{AB}$ admixture for all concentrations, however, for the H-AA admixture it was not found for the first three measurements (low concentrations). This may indicate that for the reactions occurring in the measurement chamber after an application of a small amount of $\mathrm{H}-\mathrm{AB}$ the Nernst equation is not applicable - they are more complex. The linear nature of dependence $U=f(\ln c)$, in agreement with the Nernst equation, which was observed by Podolak et al [25] and others, dealt with the influence of $\mathrm{KCl}$ on changes in the transmembrane voltage using similar measuring equipment as in the presented experiment. This suggests that the influence of the humic acids on model membranes is similar to the influence of $\mathrm{KCl}$ on the membranes. Figure 10c presents changes in the resistance of $R$ membranes (resistance on $1 \mathrm{~cm}^{2}$ of surface), before and after adding humic acid. The initial $R_{1}$ membrane resistance is shown in black while gray shows the final $R_{2}$ resistance after reaching the maximum concentration for a given humic acid in the measurement chamber. The presence of both HA-A and HA-B caused a definite increase in membrane resistance. Probably the humic acid admixtures first combine with cations in the measurement chamber. Then they are attracted to the surface of the membrane. Such an interaction can generate both transmembrane voltage and increased membrane resistance in the presence of humic acids.

\section{Conclusions}

The study shows that natural and model forms of humic acids differ in their effects on the activity of tested membrane models. This effect is particularly evident in changes of the $F$ parameter for DPPC liposomes. In EYL liposomes, the changes were minor. This effect was probably related to the state of the phase in which the membranes was found. The study was conducted at room temperature $\left(22^{\circ} \mathrm{C}\right)$, in which membranes of DPPC liposomes were in the gel phase, while EYL membranes were in the liquid crystal phase. Presumably, a membrane - based liquid crystal can not 'see' HAs molecules as clearly as when they are 
in the gel phase. Computer simulations have shown [26-28] that in the liquid crystal phase, the membrane may have numerous gaps in the hydrophilic part. This is related to the mobility of molecules, and therefore the ability to dissolve the admixtures in a given phase. Our previous work indicates [26] that macromolecules may differ substantially in their effect on the membranes of liposomes DPPC and EYL. We would argue, that strong differences in the interaction of HA-A and HA-B on parameter F in DPPC liposomes can result from the transport of humic acids connected to the metal ions inside the membranes (xenobiotics present in the environment and humic acids forming stable organo-metallic complexes).

Alloway [29] showed that the bioaccumulation ability of organometallic complexes may cause changes in the electrical charge of the membrane. An additional factor which describes the interactions between the components of the membrane and the environment is the $\mathrm{pH}$ of the system and the mobility of humic substances in different environments and the shifting balance of acid-base groups present in the lipid membrane [13]. Simultaneously, the content of organic carbon in the applied solutions of humic acids showed considerable variation in quantity, which determined their mobility and ability to form complexes with metals.

The influence of organo-metallic complexes on the surface layer of membranes and theoretical considerations have been described [27, 28]. Experiments with trans-membrane voltage confirmed significant differences between the effects of HA-A and HA-B on the membranes. When the membrane separating the measuring chamber was under the influence of HA-A admixtures there was increased electrical resistance. This can attest to the stiffening structure and gradual blocking of the transportation of ions located on both sides of the membrane.

A clear understanding of physical, chemical and electrical properties of cell membranes can be useful in the study of mechanisms involved in the transport of substances and information across biological membranes. This has also been suggested by other authors [13-16].

\section{Acknowledgements}

We thank Dalia Gosik, native speaker, for proofreading.

\section{References}

[1] Barancikova G, Makovnikokova J. The influence of soil humic acid quality on sorption and mobility of heavy metals. Plant Soil Environ. 2003;49:565-571. http://www.agriculturejournals.cz/ publicFiles/52956.pdf.

[2] Grassi M, Rosa M. Humic acids of different origin as modifiers of cadmium-ion chemistry: A spectroscopic approach to structural properties and reactivity. Inorg Chim Acta. 2010;363:495-503. DOI: 10.1016/j.ica.2009.07.033.

[3] Jamroz E. Właściwości próchnic gleb leśnych pod zaroślami kosodrzewiny w Rezerwacie Śnieżnik Kłodzki [Properties of soil organic matter in the forest soils under mountain dwarf pine in the Snieznik Klodzki Reserve]. Sylwan. 2012;156(11):825-832. http://yadda.icm.edu.pl/yadda/element/bwmeta1.element.agrod61e6f8a-e7de-4914-b52e-1f959e6d2e95.

[4] http://www.humicsubstances.org/index.html.

[5] Feller Ch, Brossard M, Chen Y, Landa ER, Trichet J. Selected pioneering works on humus in soils and sediments during the $20^{\text {th }}$ century: A retrospective look from the International Humic Substances Society view. Phys Chem Earth. 2010;35:903-912. DOI: 10.1016/j.pce.2010.10.004.

[6] Filella M, Hummel W. Trace element complexation by humic substances: issues related to quality assurance. Accred Qual Assur. 2011;16:215-223. DOI: 10.1007/s00769-010-0716-3. 
[7] Gonzalez Perez M, Martin-Neto L, Saab SC, Novotny EH, Milori DMBP, Bagnato VS, et al. Characterization of humic acids from Brazilian Oxisol under different tillage systems by EPR, ${ }^{13} \mathrm{CNMR}$, FTIR and fluorescence spectroscopy. Geoderma. 2004;118:181-190. DOI: 10.1016/S0016-7061(03)00192-7.

[8] Jerzykiewicz $\mathrm{M}$. The effect of $\mathrm{Hg}$ (II) ions on the free radicals of humic substances and their model compound. Chemosphere. 2013;92/4:445-450. DOI: 10.1016/j.chemosphere.2013.01.048.

[9] Filip Z, Kubat J. Microbial utilization and transformation of humic substances extracted from soils of long-term field experiments. Eur J Soil Biol. 2001;37:167-174. DOI: 10.1016/S1164-5563(01)01080-9.

[10] Man D. Fluidity of liposome membranes doped with organic tin compounds: ESR study. J Liposome Res. 2008;182:225-234. DOI: 10.1080/08982100802309461.

[11] Shimshick EJ, McConnell HM. Lateral phase separation in phospholipid membranes. Biochemistry. 1973;12:2351-2360. https://www.jstor.org/stable/62988?seq=1\#page_scan_tab_contents.

[12] Hagelueken G, Duthie FG, Florin N, Schubert E, Schiemann O. Expression, purification and spin labelling of the ferrous iron transporter FeoB from Escherichia coli BL21 for EPR studies. Protein Express Purificat. 2015;114:30-36. DOI: 10.1016/j.pep.2015.05.014.

[13] Petelska AD, Naumowicz M, Figaszewski ZA. The influence of $\mathrm{pH}$ on Phosphatidylethanolamine monolayer at the air/aqueous solution interface. Cell Biochem Biophys. 2013;65:229-235. DOI: 10.1007/s12013-012-9424-4.

[14] Choudhry GG. Humic Substances: Structural, Photophysical, Photochemical and Free Radical Aspects and Interactions with Environmental Chemicals. New York: Gordon and Breach Science Publishers, Inc. 1984. https://www.cabdirect.org/cabdirect/abstract/19841989409.

[15] Conclin Jr AR. Introduction to Soil Chemistry. New Jersey: John Wiley \& Sons, Inc.; 2014:274-287. DOI: $10.1002 / 0471728225$.

[16] Marita JM, Hatfield JRRD, Chapple C. NMR characterization of lignins in Arabidopsis altered in the activity of ferulate 5-hydroxylase. Proc Natl Acad Sci USA. 1999;96(22):12328-12332. DOI: 10.1073/pnas.96.22.12328.

[17] Schnitzer M, Khan SU. Soil Organic Matter. Amsterdam: Elsevier Sc. Publ. Co; 1978. http://store.elsevier.com/Soil-Organic-Matter/isbn-9780080869759/.

[18] Man D, Pisarek I, Braczkowski M. The impact of humic substances on the liposome structures: ESR method. Nukleonika. 2013;58(3):439-442. http://www.nukleonika.pl/www/back/full/vol58_2013/v58n3p439f.pdf.

[19] Singleton WS, Gray MS, Brown ML, White JL. Chromatographically homogeneous lecitin from egg phospholipids. J Am Oil Chem Soc. 1965;42:53-56.

[20] Hemminga MA. Interpretation of ESR and saturation transfer ESR spectra of spin labeled lipids and membranes. Chem Phys Lipids. 1973;32:323-383.

[21] Stuart BH. Infrared Spectroscopy: Fundamentals and Applications. New Jersey: John Wiley Sons. Ltd.; 2004. DOI: $10.1002 / 0470011149$.

[22] Rodríguez FJ, Schlenger P, García-Valverde M. Monitoring changes in the structure and properties of humic substances following ozonation using UV-Vis, FTIR and ${ }^{1} \mathrm{H}$ NMR techniques. Sci Total Environ. 2016; 541:623-637. DOI:org.sd.han.uni.opole.p1/10.1016/j.scitotenv.2015.09.127.

[23] Man D, Pisarek I, Braczkowski M, Pytel B, Olchawa R. The impact of humic substances on the liposome structures: ESR method. J Liposome Res. 2014;24:106-112. DOI: 10.3109/08982104.2013.839998.

[24] Yasuda S, Hamaguchi E, Asano K. Ready chemical conversion of acid hydrolysis lignin into water-soluble lignosulfonates. III. Successive treatment of acid hydrolysis lignin and lignin model compounds by phenolation and aryl-sulfonation. J Wood Sci. 1999;45:245-249. DOI: 10.1007/BF01177733.

[25] Podolak M, Engel G, Man D. Effect of organic compounds of tin on the electric properties of model membranes. Zeit Naturforsch. 2006;61c:453-457.

[26] Christoforidis KC, Un S, Deligiannakis Y. Effect of metal ions on the indigenous radicals of humic acids: high field Electron Paramagnetic Resonance study. Environ Sci Technol. 2010;44:7011-7016. DOI: 10.1021/es101708f.

[27] Witwicki M, Jerzykiewicz M, Jaszewski A, Jezierska J, Ozarowski A. Influence of Pb(II) ions on the EPR properties of the semiquinone radicals of humic acids and model compounds: High field EPR and relativistic DFT studies. J Phys Chem A. 2009;113(51):14115-14122. DOI: 10.1021/jp906289d.

[28] Jajić I, Wiśniewska-Becker A, Sarna T, Jemioła-Rzemińska M, Strzałka K. EPR spin labeling measurements of thylakoid membrane fluidity during barley leaf senescence. J Plant Phys. 2014;171:12:1046-1053. DOI: 10.1016/j.jplph.2014.03.017.

[29] Alloway BJ. Heavy Metals in Soils. Dodrecht: Springer Science Business Media; 2013. DOI: 10.1007/978-94-007-4470-7. 